\title{
A mulher no jornalismo brasileiro: o mundo do trabalho delas no mais antigo e no mais vendido jornal do país
}

\section{Ana Paula Bandeira ${ }^{1}$}

\section{Resumo}

O presente trabalho analisa os contextos do aumento da população feminina no jornalismo a partir das percepções de mulheres e homens jornalistas que atuam no mais antigo impresso brasileiro, o Diário de Pernambuco, e o jornal com maior circulação no país (IVC 2018), o Super Notícia, de Minas Gerais. A partir, sobretudo, dos anos 1970, as mulheres trabalham cada vez mais nas redações de jornais brasileiros. Por meio da pergunta "Em que medida a maior presença delas altera as rotinas diárias das redações?", nos questionamos sobre o fato de essas mulheres estarem ou não rompendo com a cultura masculina existente no jornalismo. Para tal, analisamos entrevistas individuais direcionadas a jornalistas de ambos os sexos dos dois veículos.

Palavras-chave: Mulher no jornalismo. Jornalistas brasileiras. Mundo do trabalho.

\section{Women in brazilian journalism: their world of work in the oldest and best-selling newspaper in the country}

\section{Abstract}

The present article analyzes the contexts of the increase of the female population in journalism from the perceptions of women and men journalists who work in the oldest brazilian newspaper, Diário de Pernambuco, and the newspaper with the largest circulation in the country (IVC, 2018), Super Notícia, from Minas Gerais. From the 1970s, women increasingly work in newsrooms of brazilian newspapers. Asking the question "To what extent does their greater presence change the daily routines of newsrooms?", we question whether or not these women are breaking with the male culture in journalism. For this, we analyzed individual interviews directed to journalists of both genders of the two newspapers.

\footnotetext{
1 Graduação em Jornalismo - Univali. Mestrado em Jornalismo - UFSC. Doutorado em Comunicação - UFPE. E-mail: a_p_bandeira@yahoo.com.br.
}

Revista Pauta Geral-Estudos em Jornalismo, Ponta Grossa, vol. 6, n. 2, p.140-152, Jul/Dez, 2019. 


\section{REVISTA PAUTA GERAL}

\section{ESTUDOS EM JORNALISMO}

10.5212/RevistaPautaGeral.v.6.i2.0009

Keywords: Women in journalism. Women brazilian journalists. Work's world.

\section{Introdução}

A mulher é maioria nas redações brasileiras. Dados mostram que $64 \%$ dos jornalistas brasileiros são do sexo feminino (MICK; LIMA, 2013). Esse percentual traz questões a serem pensadas a partir do jornalismo e do gênero. Desde os anos 1980, são inegáveis as mudanças nas redações e nos cargos executivos das empresas jornalísticas. Porém, os estudos globais sobre a cultura das redações, considerando os avanços até aqui e prospectando o futuro, aponta mais de meio século como tempo necessário para que as mudanças iniciadas no fim do século $X X$ evoluam para uma igualdade de gênero nas redações (IFJ, 2009).

Este artigo busca compreender as realidades e as adversidades vivenciadas por essas mulheres que passaram a ocupar majoritariamente as redações e também postos de comando. Interessam-nos, portanto, as percepções dos profissionais acerca das práticas e rotinas jornalísticas a partir do aumento do número de mulheres neste campo de trabalho. Por meio da técnica de entrevista em profundidade semiestruturada, nossa pesquisa empírica centrou-se nas falas de 14 jornalistas que atuam em dois veículos de comunicação brasileiros: o de maior circulação e o mais longevo, em circulação. Assim, entrevistamos profissionais do Super Notícia ${ }^{2}$ (maior circulação) e do Diário de Pernambuco ${ }^{3}$, mais antigo periódico da América Latina. Em cada redação, entrevistamos sete jornalistas mulheres e homens com cargos de edição.

\footnotetext{
2 O Super Notícia foi lançado em $1^{\circ}$ de maio de 2002 pelo Grupo Editorial Sempre Editora. Em formato tabloide $(35 \mathrm{~cm} \times 26 \mathrm{~cm})$, o veículo diário é conhecido no Brasil por seu fenômeno de vendagem. A linha editorial é sustentada no tripé (1) esporte, (2) polícia e (3) celebridades. O jornal Super Notícia circula em 48 dos 853 municípios da Grande BH e região metropolitana - uma população estimada de 5,8 milhões de habitantes. Em 2018 o Super Notícia registrou média de 145 mil exemplares em circulação por dia (IVC, 2018, por e-mail). Uma característica forte do Super Notícia é a venda avulsa. Dos 145 mil jornais em circulação, 137 mil são adquiridos via venda avulsa.

3 Em 7 de novembro de 1825 foi publicada a edição número 1 do Diário de Pernambuco. São 193 anos de atividade. O jornal era comandado pelos Diários Associados até que, em 2015, passou para o controle do grupo de mídia Sistema Opinião de Comunicação, do Grupo Hapvida, que adquiriu mais de $50 \%$ das ações dos Diários Associados, na região nordeste. No fim do mesmo ano o Grupo R2 assumiu o controle de $78 \%$ das ações do jornal, ao adquirir as cotas da Hapvida e também dos Diários Associados.
}

Revista Pauta Geral-Estudos em Jornalismo, Ponta Grossa, vol. 6, n. 2, p.140-152, Jul/Dez, 2019 


\section{REVISTA PAUTA GERAL}

\section{ESTUDOS EM JORNALISMO}

10.5212/RevistaPautaGeral.v.6.i2.0009

Por ser "um recurso metodológico que busca, com base em teorias e pressupostos definidos pelo investigador, recolher respostas a partir da experiência subjetiva de uma fonte, selecionada por deter informações que se deseja conhecer" (DUARTE, 2006, p. $62)$, optamos pela entrevista em profundidade. Foram elaborados conjuntos de perguntas com diferentes temáticas, mas nos centramos nas questões de gênero que perpassam o ambiente de trabalho e os processos de produção jornalística. Preferimos não identificar os profissionais que nos concederam entrevista. Assim, numeramos cada pessoa com os números de 1 a 7 , seguido das letras $A$ e $B$, que correspondem a cada um dos veículos.

\section{Cultura jornalística heteronormativa}

A preocupação teórica com o gênero como uma categoria de análise é algo muito recente. Emergiu no fim do século XX (SCOTT,1995). A autora divide o gênero em duas partes: (1) um elemento constitutivo e relações sociais baseadas nas diferenças entre os sexos e (2) uma forma primária de dar significado às relações de poder. O pensamento sobre os efeitos do gênero nas relações sociais e institucionais apontado por Scott nos possibilita problematizar as naturalizações, as diferenças e outras nuances do gênero no mundo do trabalho do jornalismo. Observa-se a partir da segunda metade do século $X X$ um movimento de ingresso feminino na prática jornalística inicialmente mais voltada a temas de variedades - um caminho que acompanha as mudanças do próprio jornalismo, no país, de modernização da imprensa e crescimento dos veículos (ABREU, 1996).

Conforme afirma Koshiyama (2001), o ambiente para a mulher jornalista, até a segunda metade do século $X X$, era basicamente de discriminação, exclusão e minoria. Inseridas nesta realidade, antes as mulheres tinham espaço, sobretudo, nos suplementos femininos das publicações jornalísticas, ou "em setores do jornalismo considerados pela opinião masculina dominante como de pouco prestígio ou de menor importância" (KOSHIYAMA, 2001, p. 36).

As discriminações de gênero marcam o cotidiano das jornalistas desde que elas ingressaram na profissão. A partir dos anos sessenta do século passado, a presença delas nas redações muda o cenário da profissão e hoje elas constituem a maioria. Sua participação no mercado e presença em todos os locais de trabalho pôs em relevo o problema da discriminação de gênero e do assédio sexual e moral contra mulheres jornalistas no Brasil (KOSHIYAMA; REIMBERG, 2018, p. 20). 


\section{REVISTA PAUTA GERAL}

\section{ESTUDOS EM JORNALISMO}

10.5212/RevistaPautaGeral.v.6.i2.0009

Em 1986, as mulheres ocupavam 36\% dos quadros de jornalistas do país e, uma década depois, esse número ultrapassava os 40\% (ROCHA, 2004). Em 2006, segundo dados do Ministério do Trabalho, 52\% das vagas de jornalista eram ocupadas por mulheres (CASADEI, 2011).

Os percentuais de ocupação trouxeram questões de gênero ao contexto da cultura profissional jornalística. "Gênero é um elemento distintivo nos modos do fazer jornalístico, bem como nas relações e hierarquias entre os profissionais e entre as próprias notícias" (VEIGA, 2012, p. 490). Ou seja, as questões de gênero influenciam na cultura profissional, que, por sua vez, interferem nos valores-notícia. E essa mesma cultura profissional que permeia a redação jornalística serve como canal de entrada dos valores incutidos na sociedade, que aparecem como "ingredientes no processo produtivo das notícias" (VEIGA, 2012, p. 491).

Quando se quer refletir sobre a relevância do jornalismo para uma sociedade e da presença da mulher nesse contexto, faz sentido olhar para o jornalismo por diferentes óticas. Uma delas, que vai nortear esta pesquisa, é a ótica interna, obtida dentro das redações, junto aos profissionais que ali atuam. Byerly e Ross (2008), ao pontuar algo como "teoria e prática" dessa realidade, compreendem existir uma lacuna entre haver mais mulheres na indústria do jornalismo e a existência de um ambiente politizado, no qual haja entendimento e vontade de mudar as formas existentes e arraigadas de reprodução da subordinação feminina.

Relatórios internacionais apontam não haver essa proporcionalidade entre ingresso de mulheres jornalistas e equilíbrio de temáticas e abordagens dos temas. Ao contrário. Pesquisas recentes revelam discrepância no que se refere à presença de homens e mulheres como fontes presentes nas matérias jornalísticas, ainda que haja avanços. A Global Media Monitoring Project (GMMP, 2015) identificou que, em nível global, entre 1995 e 2015, a presença de mulheres como fontes de matérias jornalísticas subiu de 17\% (em 1995) para 24\% (em 2015). Os países da América Latina tiveram o melhor resultado (16\% de aumento). Duas décadas atrás, a participação feminina nas matérias era de $13 \%$. Passado esse período, observou-se que elas estão presentes em $29 \%$ dos conteúdos.

Evidenciam-se, por meio dos produtos dos veículos de comunicação, que os valores sociais vigentes e dominantes em nossa sociedade incutem um padrão que alguns estudiosos chamam de heteronormatividade (BUTLER, 2003), calcado numa 


\section{REVISTA PAUTA GERAL}

\section{ESTUDOS EM JORNALISMO}

10.5212/RevistaPautaGeral.v.6.i2.0009

"normativa" ocidental, que parte da premissa da heterossexualidade e organiza valores e comportamentos a partir da diferença anatômica entre homens e mulheres. Essa heteronormatividade se espraia para dentro das redações na forma de cultura profissional. A hegemonia sexual modela questões sexuais, políticas e econômicas (BUTLER, 2015) e essa prática pouco depende (ao menos não é decisiva, como mostram as pesquisas) da maior ou menor presença feminina entre os jornalistas.

No jornalismo, que é aqui nosso objeto de análise, as profissionais mulheres estão em grande número entre as repórteres, também na edição e subedição, assim como estão (em menor número, mas estão) no estágio mais alto da hierarquia, como editoraschefes e diretoras de jornalismo. O crescimento vertical na carreira parece natural, à medida que as jovens profissionais recém-formadas nos anos 1990 e 2000 passam a estar entre os grupos mais experientes (sobretudo se pensarmos sob a perspectiva de que o jornalismo é uma profissão eminentemente jovem). Entretanto, quanto mais alto o posto hierárquico, menos mulheres há neles (MICK; LIMA, 2013).

Sabe-se, hoje, que a maioria dos jornalistas são mulheres jovens, na faixa até os 35 anos, têm curso superior em jornalismo, especialização em nível de pós-graduação, possuem vínculos empregatícios precários e são multiplataformas (FIGARO, 2013; NONATO, 2013). A pesquisa de Jorge, Ramalho e Ribeiro (2014), com mulheres jornalistas em cargos de chefia, considerou que as profissionais entendem que, para chegar a uma posição de comando ou para desenvolver trabalhos mais complexos, precisam trabalhar mais que os colegas homens, a fim de mostrar que são capazes. Algo que nos remete à Veloso (2013), que, após mapear a situação laboral da mulher na mídia de 11 países e entrevistar 14 mulheres jornalistas, indica haver uma conversão de diferenças biológicas em diferenças políticas, que, naturalmente, denota dificuldade para as mulheres no trabalho.

\section{Os jornalistas e as concepções de gênero}

Pela natureza da nossa pesquisa, centramos nosso olhar sobretudo nas mulheres que compõem esse grupo profissional, porém, cientes da importância de olhar para a experiência coletiva dessa classe trabalhadora, entrevistamos profissionais de ambos os sexos. Foram oito mulheres e seis homens entrevistados. No jornal $A$, três homens e quatro mulheres nos concederam entrevistas. A mais nova profissional, com 27 anos, é editora assistente. A mais velha, com 72, é colunista. Dos sete profissionais, quatro têm 


\title{
REVISTA PAUTA GERAL
}

\section{ESTUDOS EM JORNALISMO}

10.5212/RevistaPautaGeral.v.6.i2.0009

filhos (duas mulheres e dois homens). Todos têm uma história longa com o jornal. Quem tem menos tempo de casa está ali há sete anos. Três jornalistas contabilizam mais de 20 anos de empresa.

Os entrevistados do jornal B têm entre 30 e 50 anos. Também lá ouvimos três homens e quatro mulheres. Dois profissionais atuam no mesmo jornal desde o período de estágio. Outras duas eram recém-contratadas. O funcionário mais antigo tem 14 anos de empresa. A mais nova, um mês. Três profissionais (todas mulheres) têm filhos.

A compreensão da cultura midiática contemporânea, como sendo baseada no mérito, seria, conforme Subtil e Silveirinha (2017), oriunda da noção pós-feminista. "Esta ideia genérica [...] tem por base a crença hegemônica de que a igualdade entre homens e mulheres foi plenamente alcançada e constitui-se como um discurso que se alia poderosamente ao do neoliberalismo" (SUBTIL; SILVEIRINHA, 2017, p. 130).

Dito de outro modo, as diferenças de gênero tendem a ser "naturalizadas". Uma leitura apresentada no relatório Mulheres no Trabalho (OIT, 2016), remete às diferenças "indiretas". Por exemplo, as empresas dizem não haver discrepância salarial entre mulheres e homens. A diferenciação, esclarecem, dá-se por cargos. O jornalista $2 A$, de 37 anos, tem essa visão, a partir de sua experiência:

\begin{abstract}
Eu nunca vi a questão do ganhar menos porque é mulher. Nas empresas que eu trabalhei, os salários eram [equivalentes ao cargo]. Se amanhã eu tô fora e uma colega assume, ela vai ganhar o salário de editor. É o salário de editor, não é o meu salário. Não é aquela história de jogador de futebol, que o cara contrata Neymar e ele vem ganhando o dobro dos outros porque ele é o Neymar. No nosso mundo nunca vi, talvez exista nos maiores jornais $(2 \mathrm{~A}, 2018$, entrevista à autora).
\end{abstract}

Globalmente, as mulheres ganham menos $24 \%$ que os homens - diferença acentuada nas profissões mais especializadas, nas quais os profissionais se caracterizam por ter formação superior (PNUD, 2015, p. 7, 43, 122). O que nos leva a pensar nas heranças do patriarcado, que precisa ser pensado não simplesmente como ideologia, e sim enquanto relações de poder (SAFFIOTI, 1987, p. 94).

Ao relembrar os enxugamentos que presenciou ao longo de sua experiência de redação, o jornalista $3 \mathrm{~A}$ ressalta que o Jornal $\mathrm{A}$ historicamente é comandado por mulheres. Quando ele ingressou no veículo, até mesmo a editora de esportes era uma 


\section{REVISTA PAUTA GERAL}

\section{ESTUDOS EM JORNALISMO}

10.5212/RevistaPautaGeral.v.6.i2.0009

mulher. A última demissão coletiva (ocorrida em março de 2018), entretanto, resultou em uma mudança exponencial na redação. Afora o comando maior, as editorias de área passaram todas ao comando de homens. "Prestei até atenção nisso, outro dia desse que a gente tava tendo uma reunião. Só tinha a editora executiva" $(3 \mathrm{~A}, 2018$, entrevista à autora). A jornalista 4A tem uma hipótese para essa recente mudança de gênero nas chefias de áreas:

[A chefia maior] se preocupou, teve uma estratégia de [promover] pessoas com quem ela podia contar mais. Por exemplo, $2 \mathrm{~A}$, ele aguenta muita coisa. $2 \mathrm{~A}$ chega de manhã e sai de meia noite e meia. [O editor de política e economia] também. Os meninos, assim, eles recebem e não reclamam. Mulher, eu acho que reclamaria mais. Então assim, por exemplo, eu acho que neste aspecto assim, talvez haja um pouco de preconceito ainda, porque a mulher tem outras atribuições (4A, 2018, entrevista à autora).

A jornalista 5A tem 45 anos e dois filhos (de 10 e 14 anos). Coordena uma equipe $100 \%$ composta por estagiários - três mulheres e um homem - e compreende que a função de chefia, de fato, parece-se com a relação mãe-filho. Demonstra isso não apenas quando se refere aos seus subordinados, mas também quando remete à relação com suas chefias. Ao falar da relação jornalismo-maternidade, relata suas duas experiências antagônicas como profissional gestante.

Eu peguei a minha primeira maternidade com uma chefe muito complicada. [...] Tanto que eu me afastei da empresa com seis pra sete meses porque eu tive inflamação na pélvis. Pra você ter ideia, eu cobria, na época, aquela denúncia de tráfico de órgãos. Eu, grávida de seis meses e meio, dava plantão na Polícia Federal o dia inteiro em pé, atrás de notícia, de informação. Eu não fui poupada pela chefia pra esse tipo de cobertura, não que eu quisesse ser poupada, mas, assim, eu não tinha a experiência que eu tenho hoje. Tanto que na segunda gravidez, eu pensei em falar com a chefe [diferente da primeira] pra dizer: "olhe, eu posso assumir algumas coisas internas, mas, assim, eu quero mais uma flexibilidade de horário. Eu quero ter o direito de poder ir fazer minhas consultas pré-natal (já perdi muita consulta pré-natal)". Quando eu pensei em falar isso, a minha segunda chefe já chegou pra mim e disse: "eu não vou tirar você da rua e deixar você na redação pra você não fazer nada, você vai assumir essa responsabilidade aqui todinha, mas aí o horário é você quem faz". Então, assim, foi muito bacana isso dela, tá? Ela me deu uma série de responsabilidades. Eu passei a fechar um caderno de guia de profissões, eu fechava a página de saúde de domingo, uma página de pets que tinha na época. Sempre fazia $n$ coisas, fora que alguns problemas de polícia que tinha do dia-a-dia que podia ser apurado por

Revista Pauta Geral-Estudos em Jornalismo, Ponta Grossa, vol. 6, n. 2, p.140-152, Jul/Dez, 2019 


\section{REVISTA PAUTA GERAL}

\section{ESTUDOS EM JORNALISMO}

10.5212/RevistaPautaGeral.v.6.i2.0009

telefone, eu também tinha essa incumbência. Mas, assim, eu pegava a hora que eu quisesse, eu tinha que entregar o material pronto, editado inclusive, tá? $\mathrm{E}$ assim, isso me fez trabalhar mais satisfeita e eu trabalhei até a véspera de a minha filha nascer (5A, 2017, entrevista à autora).

Editora de site, 5A vivenciou diferenças culturais de gênero em momentos da carreira de repórter. Por exemplo, em 2000, quando uma cobertura policial a levou a uma cidade no interior do seu Estado, onde ficou hospedada por três meses. Ao longo do período, levou alguns furos dos colegas jornalistas concorrentes pelo fato de ser mulher. Nas noites do município interiorano, os policiais e os jornalistas homens encontravam-se no cabaré. Lá, em clima de informalidade, informações importantes eram reveladas e viravam notícia. Como o lugar era "não recomendado" às mulheres, $5 \mathrm{~A}$ ficava sem esse canal de comunicação.

\section{O trabalho e as relações com a vida familiar}

A rotina de trabalho na redação, como é descrita pelas profissionais que se tornaram mães em meio à trajetória profissional, assemelha-se no universo de todas as profissionais dos veículos que são objeto deste trabalho. Um dos grandes desafios das mulheres com filhos ainda é equilibrar as questões de família e trabalho (GMMP, 2015). Nonato (2013) realizou uma pesquisa com profissionais de São Paulo e identificou que "para a mulher, ter filhos também significa abrir mão de cargos de chefia e de uma melhor remuneração" (NONATO, 2013, p. 197). A forma como se dá a produção jornalística foi decisiva para a profissional brasileira $5 \mathrm{~B}$, de 43 anos, declinar de uma proposta de promoção, de redatora para subeditora:

\footnotetext{
Eu sei que o subeditor não é o editor, mas ele não é o redator, então ele tá ali tomando porrada de todo lado. Ele é demandado pelo repórter e demandado pelo chefe, ele não pode chegar aqui às duas tarde e não saber que cortaram a cabeça de uma mulher lá em Caratinga, entendeu? Então ele tem que tá o tempo todo ligado. E isso, pra mim, nesse momento, não encaixa na minha vida. Talvez, depois que o meu menino estiver alfabetizado, fazendo o para casa [tarefa escolar] dele sozinho, se virando um pouco mais sozinho, tudo bem, mas, nesse momento, eu prefiro perder dinheiro (5B, 2018, entrevista à autora).
}

Foi a primeira proposta de promoção desde 2012, quando ela começou a trabalhar nesse jornal, já como redatora. 


\section{REVISTA PAUTA GERAL}

\section{ESTUDOS EM JORNALISMO}

10.5212/RevistaPautaGeral.v.6.i2.0009

A jornalista 3B tem hoje 33 anos e um filho de três. Ao se formar, passou em uma seleção para trainee da Folha de S. Paulo, jornal onde trabalhou por quatro anos e meio. Lembra de uma rotina de dedicação quase exclusiva ao trabalho na capital paulista, onde vivia sozinha. De se estender por 12 horas na redação e, ao chegar em casa, checar e responder e-mails profissionais. Nesse ritmo, ela aprendeu a ser jornalista, na prática. E terminou por empreender um modo de trabalho pessoal pautado na intensidade. Ao deixar a Folha e começar a trabalhar no portal de notícias G1, em sua cidade natal, estranhou ao ver que os colegas faziam ginástica laboral coletiva e pausa para um lanche no meio da manhã.

Quando veio a maternidade surgiram seus maiores conflitos pessoais. O retorno da licença maternidade (momento em que já trabalhava no portal de notícias do grupo de comunicação onde atua hoje) e os transtornos envolvendo tempo de trabalho, horário para buscar o filho na creche e revezamento de divisão dos cuidados do bebê com o marido a fizeram "pifar", conforme suas palavras. "Aqueles três meses [pós-licença maternidade] foram meu pior momento no jornal". A decisão de deixar o jornalismo online veio concomitante ao convite para trabalhar em uma revista segmentada sobre primeira infância. Lá a jornalista 3B trabalhou até julho de 2018. Foi quando a revista faliu. Seu retorno ao jornalismo diário, no jornal $\mathrm{B}$, se deu um mês antes deste trabalho de campo. $\mathrm{E}$ aconteceu conforme o que ela chamou de "restrições para o trabalho":

Entrei em contato com o editor executivo aqui do jornal perguntando se tinha alguma vaga e tal, e falando pra ele que o meu horário, na verdade, agora é bem restrito. Não consigo trabalhar à noite por causa do meu filho. Eu e meu marido ${ }^{4}$ já temos um esquema muito certinho assim de cuidar, então eu só consigo de manhã, e ele falou "coincidentemente a única vaga que tem disponível é de manhã, é de cidades, tem tudo a ver com você e tal" (3B, 2018, entrevista à autora).

Percebemos que, entre os homens, a percepção de que há alterações e interferências na rotina de trabalho, em razão da paternidade, é exceção. A maioria, entre os jornalistas pais, não relacionou uma realidade à outra. Mesmo entre os que avaliam haver dificuldades em administrar a rotina, há profissionais que argumentam que a falta de tempo com os filhos é justificável pela natureza da profissão e que o cônjuge (todos

\footnotetext{
${ }_{4} \mathrm{O}$ marido de $3 \mathrm{~B}$ é jornalista de um portal de notícias e trabalha das $16 \mathrm{~h}$ às $23 \mathrm{~h}$, diariamente.
}

Revista Pauta Geral-Estudos em Jornalismo, Ponta Grossa, vol. 6, n. 2, p.140-152, Jul/Dez, 2019. 


\section{REVISTA PAUTA GERAL}

\section{ESTUDOS EM JORNALISMO}

10.5212/RevistaPautaGeral.v.6.i2.0009

são casados com as mães das crianças) supre a lacuna. De modo que o tempo e dedicação ao trabalho não mudam.

O jornalista $1 \mathrm{~A}$ é editor e casado com uma repórter do mesmo jornal. Tiveram filhas gêmeas cinco anos atrás. Ele se mostra envolvido e partícipe da rotina das crianças. Por exemplo, desde que mudou de função e horário, alterou o horário de aula das crianças de modo a passar o turno da manhã em família, o que lhe permite acompanhar as tarefas escolares e o cotidiano das crianças. Ainda assim, percebe o mercado de trabalho pouco tolerante às demandas familiares.

Eu acho que talvez isso seja em toda área, não só no jornalismo, em várias áreas, né? Porque, quando uma mulher vai ter filho, então já tem aquele período todinho de licença. Depois, mesmo que volta, normalmente é a mulher que cuida da criança, então ela já não pode mais viajar tanto como viajava antes, ela tem umas preocupações, não sei se tem medo de repente começar a faltar, tal. Quando a minha mulher teve [as filhas] fizemos um pacto: não pode usar nunca a criança como um argumento [para não cumprir uma tarefa de trabalho]. Senão fica um profissional com $10 \%$ a menos [na visão dos chefes] (1A, 2018, entrevista à autora).

Assim Traquina resume os efeitos nocivos que as longas e irregulares horas de trabalho têm sobre a vida do jornalista: "problemas de saúde, casamentos desfeitos, família adiada, economias fracas e ausência da vida privada" (TRAQUINA, 2005, p. 53). A segunda filha de 4A nasceu em 1990, ano em que ela se formou. A bebê tinha um mês quando ela conseguiu seu primeiro trabalho: repórter em uma TV no interior do estado onde mora. Os primeiros meses na reportagem foram tão intensos que a jornalista deixou de amamentar e delegou os cuidados da filha recém-nascida e da mais velha, então com 2 anos, à mãe (avó da criança).

Eu viajava enlouquecidamente. Eu era a repórter que mais viajava. Chegava em casa acabada. Com duas pequenas. E eu só queria cama para dormir. E ela acordava à noite, e eu dizia: não vou conseguir levantar. Às vezes mamãe levantava também... aí a gente conseguiu uma babá. Eu sei que no final das contas, meu marido disse: sua filha precisa de você. Ela tinha uns poucos meses e tava adoecendo muito, chegou a ser internada. Eram vários problemas, diarreia, gripe, imunidade baixa... só que eu tinha um negócio com o trabalho... que eu tinha que trabalhar. Eu sempre fui muito focada no trabalho. A gente tinha uma babá, que a gente achava perfeita. Quando eu cheguei num dia, o meu marido tinha demitido a babá. Aí eu disse, você demitiu, por quê? 'porque sua filha precisa de você, entendeu? você tem que parar. Ela precisa de você'. Eu esculhambei com ele, mas depois comecei a

Revista Pauta Geral-Estudos em Jornalismo, Ponta Grossa, vol. 6, n. 2, p.140-152,

Jul/Dez, 2019 


\section{REVISTA PAUTA GERAL}

\section{ESTUDOS EM JORNALISMO}

10.5212/RevistaPautaGeral.v.6.i2.0009

perceber isso. Aí fui dando uma desacelerada para ficar com as meninas, e estabelecendo horários na televisão, que antes eu não tinha (4A, 2018, entrevista à autora).

E foi justamente o ajuste nos horários que rendeu a demissão de $4 \mathrm{~A}$.

Eu cheguei de uma viagem pela tarde, dessas matérias frias. Eu disse [para a chefe]: vou pra casa, que eu tô muito cansada. Ela disse: não, você vai gravar o off. Eu disse: não vou, não tenho condições de gravar esse texto hoje, e essa matéria não vai entrar hoje. Preciso ir pra casa (4A, 2018, entrevista à autora).

\section{Consideraçôes finais}

Dentro das redações, grande parte dos profissionais não costuma pensar, tampouco problematizar, as razões por que hoje há mulheres por todas as editorias, espalhadas por diferentes cargos e com distintas funções. Até mesmo porque muitos já entraram no mercado à luz dessa realidade pós anos 1990. Ao estimulá-los a falar do tema, entretanto, pudemos observar profissionais abertos a discussões sobre gênero, tanto para falar em equilíbrio quanto para refletir sobre desigualdades camufladas ou mesmo escancaradas.

Se quantitativamente a relação é atualmente equilibrada, nas redações, esses números não são sinônimo de igualdade. Tampouco a igualdade é conquistada com a ocupação de cargos de chefia por mulheres. No entanto, a equidade efetivamente existe quando se dá na cultura organizacional. Neste trabalho, contudo, observamos que, a despeito de mulheres ocuparem postos mais altos na hierarquia, seus relatos demonstram que, por uma exigência do mercado, sacrificam suas vidas pessoais e familiares. Quando não se dispõem à dedicação total ao trabalho - que pressupõe colocar a vida privada em segundo plano -, terminam aceitando cargos e salários mais baixos dentro da redação.

Autores como Mick e Lima (2013) identificaram que, no Brasil, apesar de haver mais mulheres no jornalismo, os níveis hierárquicos mais altos são majoritariamente ocupados por homens. Nos dois jornais objeto de trabalho deste artigo, a malgrado da pesquisa de Mick e Lima, as editoras-chefes são mulheres.

Essa ascensão feminina a postos de liderança não garantem um ambiente mais favorável à mulher jornalista. Para ascender profissionalmente, é condição sine qua non que cumpram longas jornadas diárias de trabalho, com disponibilidade inclusive após o expediente, e releguem demandas relativas à maternidade, família, lazer e até mesmo a 


\section{REVISTA PAUTA GERAL}

\section{ESTUDOS EM JORNALISMO}

10.5212/RevistaPautaGeral.v.6.i2.0009

própria saúde. Ou seja, prevalece a cultura organizacional que exige produtividade e disponibilidade sem levar em consideração as questões inerentes ao gênero.

\section{Referências}

ABREU, Alzira Alves de (Org.). A imprensa em transição: o jornalismo brasileiro nos anos 50. Rio de Janeiro: Fundação Getúlio Vargas, 1996.

BUTLER, Judith. Problemas de gênero: Feminismo e subversão da identidade. Rio de Janeiro: Civilização Brasileira, 2003.

BUTLER, Judith. CORPOS QUE IMPORTAM. Sapere Aude, Belo Horizonte, v. 6, n. 11, p.12-16, 2015. Tradução de Magda Guadalupe dos Santos e Sérgio Murilo Rodrigues.

BYERLY, Carolyn M.; ROSS, Karen. Women \& media: a critical introduction. Massachusetts: Blackwell Publishing, 2008.

CASADEI, Eliza Bachega. A Inserção das Mulheres no Jornalismo e a Imprensa Alternativa: primeiras experiências do final do século XIX. Alterjor: Jornalismo Popular e Alternativo, São Paulo, v. 3, n. 1, p.1-10, jan. 2011. Semestral.

DUARTE, Jorge. Entrevista em Profundidade. In: DUARTE, Jorge; BARROS, Antonio (Org.). Métodos e Técnicas de Pesquisa em Comunicação. São Paulo: Atlas, 2006. p. 62-83.

FIGARO, Roseli. Perfis e discursos de jornalistas no mundo do trabalho. In: FIGARO, Roseli (Org.). As mudanças do mundo do trabalho do jornalista. São Paulo: Salta, 2013. p. 7-143.

IFJ, International Federation Of Journalists. Getting the balance right: Gender equality in journalism. Bruxelas: International Federation Of Journalists, 2009.

IWMF, International Women's Media Foundation. Global Report on the Status of Women in the News Media. Washington: Iwmf, 2011.

JORGE, Thaïs de Mendonça; RAMALHO, Alzimar; RIBEIRO, Laís di Giorno. Mulheres no comando de redações: questões sobre a influência das mulheres jornalistas no processo de seleção de notícias. In: ENCONTRO NACIONAL DE PESQUISADORES EM JORNALISMO, 12., 2014, Santa Cruz do Sul. Anais... . Santa Cruz do Sul: Sbpjor, 2014. p. 1 - 16.

KOSHIYAMA, Alice Mitika. Mulheres jornalistas na imprensa brasileira. In: BARBOSA, Marialva (Org.). Estudos de jornalismo. Campo Grande: Intercom, 2001. p. 33-41.

KOSHIYAMA, Alice Mitika; REIMBERG, Cristiane Oliveira. Sentido do trabalho, sofrimento e prazer para as trabalhadoras jornalistas. In: AGUIAR, Leonel; SILVA, Marcos Paulo da; MARTINEZ, Monica (Org.). Desigualdades, relações de gênero e estudos de jornalismo. São Paulo: Life Editora, 2018. p. 19-34.

Revista Pauta Geral-Estudos em Jornalismo, Ponta Grossa, vol. 6, n. 2, p.140-152, Jul/Dez, 2019. 


\section{REVISTA PAUTA GERAL}

\section{ESTUDOS EM JORNALISMO}

10.5212/RevistaPautaGeral.v.6.i2.0009

MICK, Jacques; LIMA, Samuel. Perfil do jornalista brasileiro: características demográficas, políticas e do trabalho jornalístico em 2012. Florianópolis: Insular, 2013.

NONATO, Cláudia. O perfil diferenciado dos jornalistas associados ao sindicato de são paulo. In: FIGARO, Roseli (Org.). As mudanças do mundo do trabalho do jornalista.São Paulo: Salta, 2013. p. 144-203.

OIT, Organização Internacional do Trabalho. Mulheres no Trabalho: Tendências 2016. Genebra: Oit, 2016.

PNUD, Programa das Nações Unidas Para O Desenvolvimento. Relatório do Desenvolvimento Humano 2015: o trabalho como motor do desenvolvimento humano. Nova York: Pnud, 2015.

ROCHA, Paula Melani. As mulheres jornalistas no Estado de São Paulo: o processo de profissionalização e feminização da carreira: As mulheres jornalistas no Estado de São Paulo: o processo de profissionalização e feminização da carreira. 2004. 238 f. Tese (Doutorado) - Curso de Programa de Pós-graduação em Ciências Sociais, Universidade Federal de São Carlos, São Carlos, 2004.

SAFFIOTI, Heleieth. O poder do macho. São Paulo: Moderna, 1987.

SCOTT, Joan. Gênero, uma categoria útil de análise histórica. Revista Educação e Realidade, Porto Alegre, v. 20, n. 2, p.71-99, jul. 1995. Trimestral. Disponível em: $<$ http://seer.ufrgs.br/index.php/educacaoerealidade/article/view/71721/40667>. Acesso em: 15 mar. 2018.

SUBTIL, Filipa; SILVEIRINHA, Maria João. Caminhos da feminização da profissão de jornalista em Portugal: da chegada em massa à desprofissionalização. In: MATOS, José Nuno; BAPTISTA, Carla; SUBTIL, Filipa (Org.). A crise do jornalismo em

Portugal. Lisboa: Le Monde Diplomatique, 2017. p. 122-133.

TRAQUINA, Nelson. Teorias do jornalismo Volume II: A tribo jornalística - uma comunidade interpretativa transnacional. Florianópolis: Insular, 2005.

VEIGA, Marcia. Gênero: um ingrediente distintivo nas rotinas produtivas do jornalismo. Estudos em Jornalismo e Mídia, Florianópolis, v. 9, n. 2, p.490-505, 2012.

VELOSO, Ana Maria da Conceição. Gênero, poder e resistência: as mulheres nas indústrias culturais em 11 países. 2013. 342 f. Tese (Doutorado) - Curso de Programa de Pós-graduação em Comunicação, Centro de Artes e Comunicação, Universidade Federal de Pernambuco, Recife, 2013.

Recebido em: 25/09/2019

Aprovado em: 22/11/2019 